\title{
Shaping Learner Responses in Question-Answer Sequences in the EFL Classroom
}

\author{
Sajjad Pouromid \\ Osaka University \\ Suita City, Osaka, Japan
}

\begin{abstract}
The construct of classroom interactional competence builds upon propositions made by the sociocultural theory of learning to explore the interactional consequences of teacher talk in the foreign language classroom. The sociocultural theory upholds learner participation as the key for learning to take place. Meanwhile, studies with a conversation analytic methodology have shown that learner participation depends in part on teachers' interactional practices or their classroom interactional competence. That is, teacher talk has the potential to shape learner contributions in the classroom and either facilitate or obstruct their participation. The present study has investigated how teacher talk can do so across question-answer sequences in two EFL classes in Japan and Taiwan in a Collaborative Online International Learning program. The microanalytic study of question-answer sequences in the data indicated that while referential questions, as opposed to display questions, are more likely to generate more elaborate learner responses, the interactional context in which questions are posed can influence their outcome as well. Among the interactional practices identified as facilitators of learners' participation were asking referential questions at TRPs, asking referential follow-up questions when a communicative breakdown emerges, teacher echoing of learner responses, and paraphrasing the referential question already asked. On the contrary, practices including self-elaboration, selfanswering, asking referential questions in or after extended teacher turns, teacher interruptions, and teacher turn completions were found to have obstructive effects on learners' responses.
\end{abstract}

Keywords: Classroom interactional competence; referential questions; conversation analysis.

\section{Introduction}

Classroom discourse research originated as an attempt to investigate what constituted effective teaching. In its early days, such research was driven by the belief that the choice of method could predict and explain failure or success in the teaching and learning process. In the particular case of the foreign language 
classroom, this led to a growing body of research primarily designed to compare the use of different methods whereby providing materials for teacher training programs that intended to transmit knowledge of how methods worked to teachers. During the 1990s, however, the demise of methods was already underway since more attention started to be paid to description rather than prescription. Several developments brought about this shift in language pedagogy.

One such development was the failure, on the part of researchers, to find any significant advantage in one method over another. As Richards (1990) noted, "studies of the effectiveness of specific methods have had a hard time demonstrating that the method itself, rather than other factors, such as the teacher's enthusiasm, or the novelty of the new method, was the crucial variable" (p. 36). Furthermore, along with the recognition of a wide range of variables influencing language learning came along skepticism regarding the potential of the application of the scientific method in producing changes in the classroom. It was in such an atmosphere that Kumaravadivelu (1994) introduced his idea of the post-method condition arguing that rather than adhering to global propositions of particular methods, teachers needed to devise their approach taking into account local and contextual factors while observing a number of what he called macro-strategies. One of these macro-strategies that gained popularity in the subsequent years was maximizing learning opportunities.

The post-method condition assigned more pivotal roles to teachers in creating learning opportunities. This, in turn, led to research describing how teachers' decisions in the classroom could facilitate or impede learning. The need for systematic observation and microanalysis of interactions to explicate classroom decisions directed attention towards Conversation Analysis (CA). CA raised awareness towards the co-construction of meaning and action in the classroom by teachers and learners. This latter point has several implications for understanding the interactional dynamics in the classroom, one of which is the importance of the construct of Classroom Interactional Competence (CIC).

CIC can be broadly defined as teachers' and learners' ability to employ interaction as a tool for mediating and assisting learning (Walsh, 2006). In other words, the central idea here is that since teaching and learning are materialized through interaction, learning opportunities can be enhanced by developing teachers' and learners' CIC (Walsh, 2011). Recent research on CIC has highlighted the importance of accommodating language learners with interactional space in the classroom that will, in turn, enhance their participation and increase their learning opportunities (Far, Farrell, \& Riordan, 2019). Although CIC is relatively a recent construct, a good number of researchers have investigated its different aspects. Sert $(2011 ; 2013)$ for instance, has studied EFL teachers' claims of insufficient knowledge and epistemic status-checks and has added to the bulk of knowledge about how teacher talk. Hosoda and Aline (2013) also investigated preferred response types in question-answer sequences in the classroom. In another study, Waer (2012) looked into how teachers' use of learners' L1 can facilitate classroom interaction. The development of research on $\mathrm{CIC}$ in recent years has led to the introduction of a few other concepts as well. 
Pertinent to CIC is the concept of shaping learner contributions (SLC), which comprises two main dimensions (Daşkın, 2015). The first one concerns encouraging learners who respond to teacher initiations to contribute more to the class discussions by avoiding giving short and simple responses. This dimension of SLC requires teachers to exploit elicitation techniques and make interactional decisions that help learners to do so. The second dimension, on the other hand, requires teachers to make sure that all other learners in the classroom, that is to say, those who are not directly involved in the interaction at the moment can completely follow and comprehend what one of their peers in the classroom has already said. This second dimension of SLC is also reminiscent of what Schwab (2011) called multilogue, a particular institutional interaction in which contributions are addressed to more than one individual. To sum this issue up, SLC ascribes dual responsibilities to teachers: first to elicit more elaborate responses from a learner and second, to make sure that all other learners can understand what is said. A look through the literature on SLC, however, shows that its first dimension seems to have attracted more attention. Walsh (2002) and Walsh and Li (2013), for example, studied the various ways teachers' interactional decisions can facilitate or impede learning. Similarly, Seedhouse (2004) investigated the role of repair and (Waring, 2009) studied the effect of adherence to lockstep and fixed interactional patterns on learner contributions in the EFL classroom.

Although there seems to exist a tacit consensus among scholars on that teachers' use of language can create or hinder learning opportunities in the classroom, the constructs of CIC and SLC still suffer from a paucity of data-driven backing. The present study will, therefore, look into two teachers' interactional practices during a Collaborative Online International Learning (COIL) program with an emphasis on how teacher interactional competence (or the lack of it) may provide learners with (or obstruct their) interactional space and learning opportunities, or in brief, shape learner contributions.

In its purest form, COIL can be defined as a form of online learning involving classes from two or more countries to heighten learners' awareness of intercultural differences (Shiozaki, 2016). Built into the context of internationalization of higher education, COIL can prove very useful in promoting intercultural competence as well as other components of communicative language ability in learners. Learners in distant areas can be brought together to enjoy cultural exchange and interaction in a shared foreign language. COIL exchanges can happen either synchronously or asynchronously. When applicable, the two classes can be held jointly, and the learners can interact via a computer interface in real-time. On the other hand, if the time gap between the two countries does not allow a live session, learners can post videos on different video sharing platforms for their peers from the other country.

Since the application of computer technology such as COIL in EFL classes has continuously gained momentum during the past decade, the present study has kept a focus on the question-answer sequences during synchronous COIL interactions among teachers and learners in two EFL classes in a Japanese university and another university in Taiwanese. Classroom interactions in the 
present study have been investigated with a Conversation Analytic (CA) methodology. In its canonical form, CA can be defined as a methodology for the investigation of naturally-occurring interactions, or to study any two or more people talking together (Have, 2012). It is a multi-disciplinary methodology that has been widely used in many different fields, including second and foreign language acquisition. The implications of $\mathrm{CA}$ for language teaching are manifold since it is well equipped to reveal the social organization of natural language-inuse. CA relies on naturally occurring data and in the case of the foreign language classroom, learner interactions can be regarded as authentic and natural within the institution of the language classroom. What is more, since CA partly focuses on the sequential organization of interactions, it is well-equipped to unravel the intricacies involved in how learners' responses are shaped by the questions teachers ask in the language classroom. That is probably why the majority of studies on CIC have adopted it as their methodological framework. In CA research, as is the case with the present study, naturally occurring data is audio or video-taped and then transcribed with as much detail and precision as possible. As shall be seen in the data analysis of this study, CA transcriptions, also known as Jeffersonian transcriptions (Jefferson, 1984), are meant to grasp both vocal and non-vocal features of the interactions so as to enable the researcher to make sense of the participants' emic perspectives (refer to the appendix for a guide to transcription symbols).

\section{Referential Questions (RQs)}

The importance of asking questions in the language classroom was first brought to attention early in the 1980s at a time when the social interaction theory of language learning was finding more proponents. Social interaction theory came to criticize cognitive views that attributed language learning to the human mind while underestimating the role of interaction. For the supporters of the interactionist view, asking questions would allow language teachers to generate more interaction in the classroom and was therefore valued. In a pivotal study, Long and Sato (1983) identified two broad types of questions often asked in the language classroom, namely display and referential questions. The two question types differed from each other in terms of the purpose behind asking them. In other words, while in display questions the answer is already known to the questioner, and the purpose is to check or evaluate the respondent's understanding, in RQs, the answer is unknown to the questioner, and it is the respondent who is expected to know the answer. Long and Sato then argued that while in real-world interactions RQs are far more frequent than display ones (76\% of all questions asked), in the language classroom RQs are not asked as frequently $(14 \%$ of all questions asked). This could have interactional consequences for the level of learner participation in the classroom as well. Brock (1986), for instance, found that RQs are more likely to elicit more elaborate and syntactically complex responses from the learners while display questions often led to very short, simple or formulaic learner contributions.

The study of question types was not limited to the heyday of interactionist perspectives towards language learning in the 80s. Nevertheless, many of the results of the research that took place during that time have been corroborated by recent research as well. Shomossi (2004), for instance, found that while 
display questions were asked more frequently in the language classroom, it was the RQs that prompted lengthier learner contributions. David (2007) also confirmed the appropriateness of RQs in generating more complex learner responses while arguing that display questions may work better for learners with limited proficiency in the second language. Alduais (2012) also concluded that asking RQs is more conducive to learner initiations in sequential interactions. It, therefore, seems that there is little doubt about the role RQs can play in promoting learner interactions in the classroom. Yet the question that remains unanswered is whether all RQs necessarily lead to enhanced participation opportunities for learners. This is what the present study sought to address. Such a question is particularly important with reference to the relatively recent shifts in how competence is conceptualized and understood in the field of language teaching. While once cognitive accounts of language learning considered competence as a set of underlying, etic and hard-wired biological endowments (Markee, 2019), it is now acknowledged that competence needs to be defined in terms of the way language learners use interactional mechanisms to establish mutual understanding with their co-participants (Salaberry \& Kunitz, 2019). This latter understanding of competence also means that teaching practices in the language classroom need to aim at extending participation on the part of learners. Let us now turn to the analysis of the data and see what interactional sequences during, before, and after asking RQs are likely to facilitate or obstruct learner contributions.

\section{The Study}

The analysis of the data showed that teachers' questioning practices in the COIL classroom led to the creation or obstruction of learning opportunities for learners. While it was found that the majority of questions asked by teachers across the data were of referential question (RQ) type, the microanalysis of the turns in interactions revealed that not all RQs led to the initiation of more extended learner turns and, as a result, space for interaction and learning. The following table summarizes the results.

Table 1: Interactional practices related to RQs and their outcome

\begin{tabular}{|c|c|}
\hline Outcome & Interactional Practice \\
\hline Facilitation & $\begin{array}{l}\text { - } \text { Asking RQs at Transition } \\
\text { Relevance Points (TRP) } \\
\text { - } \text { RQ follow-ups (clarification } \\
\text { requests) at communicative } \\
\text { breakdowns } \\
\text { - } \text { Teacher echoing } \\
\text { - Paraphrasing an RQ }\end{array}$ \\
\hline Obstruction & $\begin{array}{l}\text { - Undue elaboration on questions } \\
\text { - Answering self-posed questions } \\
\text { - Prolonged teacher turns } \\
\text { - Undue interruptions } \\
\text { - Completion of learner turns }\end{array}$ \\
\hline
\end{tabular}

In what follows the interactional practices found to lead to either facilitation or obstruction of learner participation opportunities will be exemplified and 
discussed along with excerpts from the interactions. As mentioned earlier on, the interactions took place among teachers and learners in two classes in a Japanese university and a university from Taiwan. For the sake of anonymity the two teachers will be referred to as JT (Japan class teacher) and TT (Taiwan class teacher) and the learners as TL1-TL18 (Taiwan class learners) and JL1-JL16 (Japan class learners). The data comprises all online interactions taking place among these teachers and learners during one semester. Both classes had the primary goal of improving English conversation skills in the learners by discussing selected cultural topics.

\subsection{Facilitation}

In what follows three excerpts from the data will be analyzed to exemplify the interactional practices that are likely to encourage extended learner participation.

\subsubsection{RQ at a Transition-relevance Point (TRP) and Paraphrase}

In Excerpt 1, where Taiwanese learners (TLs) are interacting with Japanese learners (JLs) via a monitor interface at the presence of the Taiwan class teacher (TT) and the Japan class teacher (JT), the topic is the range of activities people can do in bars in Japan. At the beginning of this sequence, a Taiwanese learner (TL12) has taken up the turn to pose a question. JT's interactional practices featured by asking RQs at the right time when a TRP (the time in a conversation when the turn at talk passes from one speaker to the next, which is often marked with acoustic and prosodic closure of the current turn) emerges and providing communication-driven paraphrase facilitates the creation of interactional space for JLs.

\section{Excerpt 1: Facilitation through RQs at TRPs and Communication-driven paraphrase}

1 TL12: ((self-selects)) in a BAR what do you USually do beside drinking? (3.0)

2 JT: in a bar what do you usually do BESIDES drinking?

3 TL12:=yes because now we have e: maybe even play DART or you can play (1.0) table tennis or maybe:::

4 JLs: ((laugh))

5 JT: PLAY? $>$ After drinking $<$ ?

6 JLs: ((laugh))

7 TLs: ((laugh))

8 JT: ok these are actually what you can DO in Taiwan (.) dart or table tennis $\downarrow$ if you are not too drunk of course $\downarrow$

9 JLs: [((laugh))

10 TLs: ((laugh))] (2.0)

11 JT: ok anything you can do in a bar in Japan?

12 JL8: e::h ((she is sitting in the back of the class but at this point stands to come to the front closer to the camera))

13 JL8: so I::: ((takes a seat in front of the screen and the camera)) I::: have never gone to bar but and there >in Japan< there are a lot o::f (.) some kind of bar like (.) to em drink with (.) dri::nkwi::th watching spo::rts>game<

14 JT: hum

15 JL8: or drinking wi::th the like DARTS play darts or nantake are ((in Japanese: what is this? With a gesture for billiard sports))

16 JL12: billiard? 
17 JL8: billiard? biliardo? biliardo ((Japanese for billiard)) ((laughs)) or like some (1.0) UUUHHHH there are (3.0) kinds o::f GAME like playing game game ball? ((looks at JL12))

18 JL12: ((nods))

19 JL8: game bar $\uparrow$ like play game $\uparrow$ video game [to

20 JT: but] not in ALL bars >I mean< if you wanna play there's [a specific

21 JL8: yes]

22 JT: bar you wanna [go to

23 JL8: yes] or like (.) drinking with the music like a just music

24 JT: live music?

25 JL8: yes

26 JT: aha $\downarrow$

27 JL8: so lots of kinds of bar (.) there are lots of kinds of bar

28 JT: [greatgreat

29 JL8: yes]

In turn 1, TL12 asks a question which is followed by a three-second silence: a duration which is usually enough for self-selection by other interlocutors in an interaction. However, since none of the JLs takes up the turn and volunteers for an answer, JT initiates a repair-driven paraphrase in turn 2 characterized by the emphatic pronunciation of the word "BESIDES" aiming to correct the use of the word "beside" by TL12. This repair, however, is provided in passing and remains unnoticed by TL12 who quickly starts another turn (notice the latching sign) elaborating on his previously asked question. The unfolding of the following turns also reveals that JT's intention in turn 2 was to paraphrase TL12's question for communication purposes since the repair was attended to neither by the learners nor the teachers later on. This could potentially create a space for JLs to gain the floor, but as mentioned before, TL12's latching turn that follows this paraphrase limits this space. Throughout turns 3 to 10 and in a post-expansion sequence the interactants make brief jokes about the idea of playing after drinking until turn 11 where JT, once again, provides a delayed communicationdriven paraphrase for TL12's question in turn 1. At this moment one of the Japanese learners (JL8) sitting at the back of the class utters a filler sound (e::h) with a prolonged vowel indicating her self-selection for the next turn. She then steps towards the front of the class where the screen, the camera, and the microphone are located. In turn 13, JL8 starts her relatively long response to the question and the paraphrased question, which continues towards the end of the sequence with minimal interruptions by JT. The only question asked by JT occurs in turn 16, which is a short form for the RQ "do you mean billiard?" as a response to JL8's request for help in turn 15. This question is asked at a time when the previous turn has come to a prosodic, syntactic and semantic end and hence a transition relevance point (TRP) has emerged. For this reason, JL8's flow of talk is not interrupted, and she continues until she brings her turn to a close.

\subsubsection{Follow-ups to RQs}

Based on the data in this study, asking follow-up questions after a response has been given to an $R Q$ allocates learners more interactional space and can elicit longer and more complex responses from them. In other words, as shown in the previous excerpts, asking RQs does not necessarily lead to longer learner 
responses, and certain accommodations need to be provided for them to serve this purpose. The following excerpt introduces another interactional practice, which has the potentials to make RQs work.

In this excerpt, JT poses a question about the responsibility of governments in Taiwan and Japan regarding food health. More specifically, he wants to know whether Taiwan and Japan have taken any measures to ban the sale of unhealthy foods in these two countries. At first, this RQ is not well received by the TL who self-selects to answer it, but in a series of interactional practices including paraphrases provided by TT and a follow-up question asked by JT, TL10 is given a chance to contribute to the interaction more.

\section{Excerpt 2: Facilitation through RQ follow-up moves and paraphrase}

1 JT: so I've I've got a question about this $\downarrow$ ehm we ALL know that >some< MOST fast foods a::re are NOT healthy and ehm probably the people in the government know that too right? So we know that they are not healthy but ehm they don't do anything that we can see: to ba::n these kinds of unhealthy food $\downarrow$ is that the case in Taiwan? Does the government take any actions for banning or limiting the number of fast food restaurants? ((to the JLs in the front row)) And I have the same question about Japan maybe you can think about that ((to all JLs)) or anybody ok if have any answers you can come to the front $\downarrow$ so first about Taiwan $\downarrow$

2 TL10: ((picks up the microphone and looks confused. Looks away from the screen to $\mathrm{TT}))(3.0)$

3 TT: ((to TL10)) ehm government tries to ban? These restaurants (.)is government doing anything to ban?

4 TL10: ((looks at the screen again)) .hhh (3.0) hi

5 JL7: ((waving at the camera)) [hi

6 JL1: hi]=

$7 \quad$ JT: $=$ hi

8 TL10: hi ((looking at the camera)) I haven't listened eh I haven't heard that government takes eh (.) some (.) practice to ban the:: dangerous restaurants cause in Taiwan like McDonalds and is (.) have no bigger ((inaudible)) (1.0) it was >normal size < for Taiwanese and is (.) ehm so:: government will not banish kind of food (.) yeah=

9 JT: $=I^{\prime} m$ sorry you said McDonold is not BIG SIZE?

10 TL10: ehm cause in (.) ehm the USA they have the:: ehm LARGE size of >hamburger< and have two or three ehm (.) piece of (.) meat=

11 JT: =hum

12 TL10: big meat yes and in Taiwan there's ehm ((looks at TT as of searching for a word)) we seldom see ((inaudible)) so we have the $>$ normal $<$ normal size ehm offered to the:: > Taiwanese $<(2.0)$

13

JT: ok $\downarrow$

JT's RQ asked in turn 1, which is delivered in an extended teacher turn faces silence and an expression of confusion on TL10's face as well as her body language. The extended teacher turns, as shall be seen in the rest of this paper, can have negative interactional consequences and limit learner contribution opportunities even when an RQ is asked. The same thing happens in turn 2. TT, however, having noticed TL10's bewilderment manifest in her facial expressions and a relatively long silence for 3 seconds, comes to her rescue. In turn 3, she paraphrases the RQ already asked by JT. TL10, who was looking at TT with an 
expression of confusion on her face, then quickly looks at the screen and the camera again signaling that she is ready to give an answer. There is another 3second pause in turn 4 , but it is not as threatening as the one in turn 2 could be since it occurs after her out-breath (.hhh) indicating that she is ready to start any second hence rendering the silence as an intra-turn one. That is why the 3second pause in her turn is no more interrupted by one of the teachers in an attempt to help her start. She does start in turn 4, and after a few greeting exchanges, she manages to deliver a relatively lengthy and complex response to the original question and its paraphrase in turn 8 . Once her turn comes to an end indicated by the emergence of a TRP in the form a falling intonation at the end of her syntactically and semantically finished segment and a case closing "yeah," however, JT's quick uptake of the turn to ask a follow-up question and clarification request, allows her a second chance to contribute to the interaction. JT could have provided a positive assessment in turn 9 and brought the sequence to an end. He, instead, posed a follow-up move, which in return necessitated another response on TL10's part. Notice how in turns 10 and 12 TL10 manages to give an elaborate response to JT's follow-up move. The sequence then comes to an end by JT's case closing " $o k$ " indicating his satisfaction with the prior response move. In short, the follow-up move to the RQ led to a more extended learner response.

\subsubsection{Teacher Echoing}

Teacher echoing of a learner turn after an RQ has been found to be another interactional practice, which can serve the purpose of eliciting more extended learner responses. Echoing can be defined as the repetition of an utterance made by a previous speaker by the current speaker. This can take different forms and may result in different interactional sequences. What is a focus here, however, is the time a teacher echoes a learner's response to an already asked RQ with the purpose of eliciting a lengthier response. The following excerpt where questions are asked about a special kind of Japanese pub or restaurant called an "izakaya" illustrates how JT's echoing of a JL's contribution provides her with an opportunity to contribute more to the class interactions.

\section{Excerpt 3: Teacher echoing of learner turns after RQ}

1 TL17: > wa-< what is (.) izakaya? ((a kind of casual Japanese restaurant for drinking and eating)) Wa- what is iza- what is izakaya?

2 JL2: uh it provides alcohol. It is which we must do alcohol. In izakaya we can drink many and many alcohol. So:: many customers drink eh? ((searching for a word and looking away from the screen)) drunk?

3 JT: get drunk $\downarrow$

$4 \quad$ JL2: get drunk too much $\downarrow$

5 JT: but it's not only for alcohol I mean you eat food and you drink alcohol=

6 JL2: =yes yes and there are also we can choose soft drink like juice (5.0)

$7 \quad$ JT: another question similar question HOW is an izakaya different from other traditional Japane:se [restaurants?

8 JL2: u:::h]

9 JT: are they the same or are they different?

10 JL11: different

11 JT: different $\uparrow$

12 JL11: main purpose is drinking $\downarrow$ (.) in izakaya 


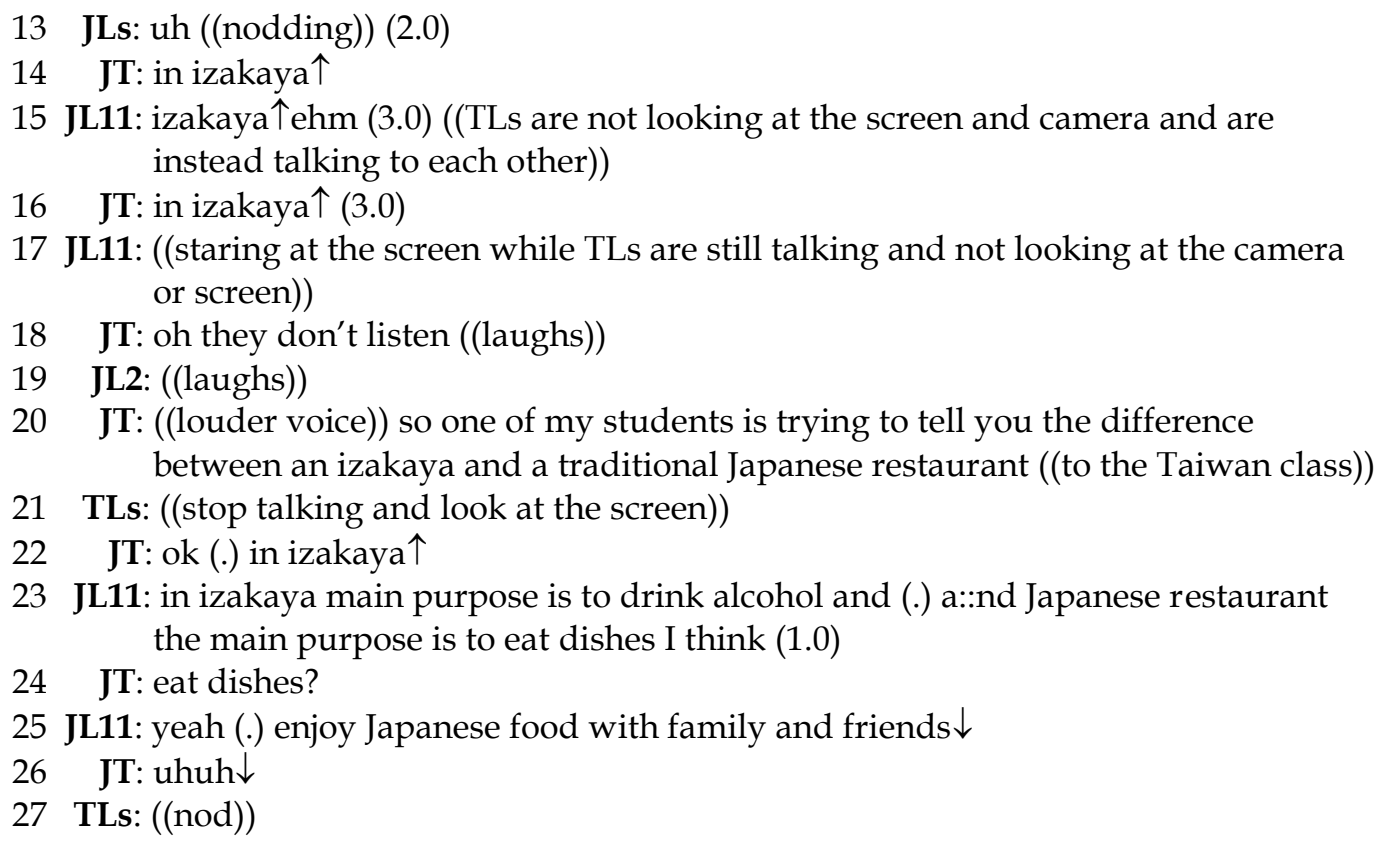

The excerpt starts with TL17's RQ about a special kind of Japanese restaurant called "izakaya." JL2, who is seated closer to the screen and the camera selfselects for the next turn and provides a response to the question. She goes on until turn 4, and in the middle, she implicitly asks for JT's help for the phrase "get drunk" towards the end of turn 1. JT evaluates JL2's comment as incomplete and prompts her to explain that izakaya is not merely a place for drinking and that food can be ordered too. After JL2 does so in turn 6 and after a long pause at the end of this turn, JT poses a similar question presumably to elicit more from JLs. In turn 9, JT also offers a simplified version of the question to scaffold JLs: JT changes his original information question to a yes/no question which is less demanding to answer. This works, and JL11 says in a short turn that traditional Japanese restaurants and izakayas are "different." JT's echoing of JL11, which has a rising intonation, functions as a follow-up move requiring JL11 to elaborate on her answer. JL11, who seems to have oriented to what is required, initiates a response in turn 12 saying "main purpose is drinking" with a falling intonation signaling the completion of her turn. After a very short pause, however, she says "in izakaya" showing her will to continue. JT who seems to have noticed JL11's wish to continue echoes her words in turn 14 with a rising intonation to signal JL11 that she can continue. At this point, a nuisance takes place that inhibits JL11's compliance with JT's demand: TLs are not looking at the camera and are instead talking to each other. This has a simple implication for JL11 who thinks that she should pause until those with whom she is interacting are listening to her. JT echoes JL11's words once again in turn 16, yet JL11 is still staring at the screen waiting for her Taiwanese peers to indicate that they are ready to listen to her. JT notices the source of trouble, and in turn 20, makes an explicit attempt to gain TLs' attention. But even after the TLs stop talking, JL11 seems to need another prompt to continue her turn, and this prompt is provided by JT in the form of one final echo in turn 22. JT echoes another utterance produced by JL11 in turn 24, and as a result, JL11 is able to bring her turn to completion with a falling intonation. 


\subsection{Obstruction}

The previous section illustrated how a teacher's interactional practices particularly regarding when and how to ask an $R Q$, may create more space for interaction in the COIL classroom. This, however, may become even more noticeable once cases featuring the opposite are also studied. In what follows three excerpts from the data will be analyzed to demonstrate how particular interactional practices may block the space for learner participation and hence limit learning opportunities.

\subsubsection{Answering self-posed questions and prolonged turns}

In Excerpt 5.6 interactional space is wasted due to the teachers' extended turn and his self-answering of an already posed question. In the following sequence, TL1 is asking her Japanese peers about echo-friendly restaurants in their home country. She, however, does not receive any response from JLs.

\section{Excerpt 4: Teacher's answering self-posed questions and prolonged teacher turn}

1 TL1: we don't know about Japan (.) like $\downarrow$ do they have such restaurant or something?

2 JT: oh well we were just discussing this and we we didn't come (.) up with any conclusion if we have actually any restaurants like that here $\downarrow$ uh do you think ((to JLs)) in Japan (.) here $\downarrow$ is there any restaurant that takes care of this thing (.)

3 JT: (5.0) food mile $\downarrow$ or envi- or $>$ being environmentally friendly<?

4 JLs: ((silently look at each other))

5 JT: No (.) probably the answer is no $\downarrow$

6 JLs: ((laugh))

7 JT: \$no answer means no\$

8 JLs: ((laugh))

9 JT: yeah $\downarrow$

TL1's question in turn 1 in this excerpt is quickly followed by JT's turn. This happens while there is no pause or silence after TL1's RQ, meaning that JLs did not literally have any chance to self-select for an answer. Within JT's relatively long response in turn 2, he paraphrases TL1's question. But notice how this paraphrase is both longer and structurally more complex than the original question posed by TL1 in turn 1. The JT's extended turn is followed by a fivesecond silence in turn 3 . Although this silence length is often long enough for the uptake of a turn by the next speaker, it cannot be considered too long due to the cognitively demanding nature of the question asked by JT in the previous turn. At this moment and while JLs are looking at each other and can possibly gain the floor any second, JT answers his own question with a "no" followed by a short pause in turn 5 . This serves as a case closing indicator particularly because it is followed by another case-closing remark "probably the answer is no" ending with a falling intonation. This raises laughter in JLs, and quickly afterward, JT makes another attempt to close the case by laughingly saying "no answer means no." It might not be possible to predict what would happen if JT had not provided an answer to his own question. What is evident, however, is that answering self-posed questions closes any window of opportunity for learner contributions. 


\subsubsection{Undue interruption and completion of learner turns}

Obstructive interactional practices after RQs are not limited to prolonged teacher turns and answering self-posed questions. Two other such practices identified in the data include undue interruptions and completion of learner turns. Turn interruption occurs when a next speaker does not wait for a TRP and cuts short a current speaker's turn. In the data, this usually happened when the teachers seemingly tried to oil the interaction with their interruptive turns while the results often proved the opposite. Turn completion, on the other hand, occurred when a potential next speaker completed a current speaker's turn presumably in an attempt to predict what the current speaker intended to say. The teachers in the data also usually did this, and the result was that what could potentially be an extended learner turn after an RQ turned to a minimal learner response. The following excerpt illustrates a few instances of turn interruption and turn completion as obstructive interactional practices following an RQ.

In excerpt 5, after a discussion with TT and TLs, JT initiates a new subtopic to ask students (primarily addressing JLs) whether they have had a negative experience about eating out. The teacher, as the current speaker who has initiated the sequence, nominates the next speakers (JL14, JL6, and JL9) explicitly. Yet, what happens after some of the RQs asked throughout the sequence proves to be inhibiting elaborate and extended learner contributions.

\section{Excerpt 5: Undue interruption and completion of learner turns}

1 JT: well another question I have is about how you react to::: I mean (2.0) bad experiences in a restaurant $>\mathrm{I}$ mean $<$ if you ORder some food and the food is too late how do you react to that I mean you GO to a restaurant you wait for thirty minutes twenty minutes your food doesn't arrive what do you do (.) maybe YOU can start $\downarrow$ ((pointing to JL6)) (2.0)

2 JL6: I don't feel bad so:: I don't feel bad can wait

3 JT: you keep waiting?

4 JL6: yeah (1.0) but (.) too (.) too long too late I I maybe I say (.) to:: (1.0) [waiter

5 JT:

6 JL6: so where is my dish? Maybe I ask but=

7 JT: =how long is too much for you like ten minutes? Twenty minutes?

8 JL6: over (2.0) over thirty minutes=

9 JT:=u::h over THIrty minutes you wait (1.0) really patient

10 JL6: ((laughs)) after $\uparrow$ (.)

11 JT: that's good after thirty minutes of waiting you will kindly and politely ask the waiter excuse [me where is my dish

12 JL6: $\quad$ ((nodding)) yeah yeah yeah]

13 JT: you don't get [angry

14 JL6: $\quad$ yeah] because I I my part time job is (.) >restaurant< so: if restaurant is busy the dish is (.) it is difficult (.) to give to::: give? The dishes to [customers

15 JT: to serve]

16 JL6: so:: (.) yeah I think the feeling (.) of waiter so I can wait [in the

17 JT: $\quad$ uh] so that's because

18 JL6: you actually are working as a part time ((inaudible)) [so

19 JT: you understand the [situation yeah]

20 JL6: yeah] ok good (.) what about you ((to JL14))

21 JL14: I think after waiting for twenty minutes I will ask waiter $\downarrow$ (1.0) 
22 JT: but how do you ask? Politely and kindly with a smile or ehm getting a little angry fisting your hand

23 JLs: [((laugh))

24 JT: punching on the table] WHERE is my FOOD? (1.0)

25 JL14: politely and [smi-

26 JT:

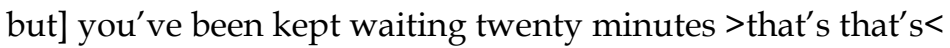

that's a lot

27 JL14: yeah=

28 JT: =but still you don't forget to smile

29 JL14: if they are very crowded I=

30 JT: $=$ u::::h [right

31 JL14: I] will ask with smile

32 JT: ok a::nd $\uparrow$ ((referring to JL9))

33 JL9: I (.) little get angry

34 JL6: ((bursts out laughing))

35 TLs: ((laugh))

36 JL9: ((laughs))

37 JT: get angry ok good and what do you do when you get angry?

38 JL9: no smiling ((laughs))

39 JL6: kowai ((Japanese for scary))

40 JL9: and ehm=

41 JT: shouting

42 JL9: sh- ((laughs)) not shouting but=

43 JT: =not shouting (.) ok how do you how do you show that you're angry I mean you should show the waiter that you are angry

44 JL9: if you you cannot serve the dish early I (.) I can go ((tries to show the outside with hand gesture)) to $\uparrow=$

45 JT: $=\mathrm{u}:$ : h you can go to another restaurant to [the

46 JL9:

to] the waiter $\downarrow$

47 JT: waiter oh yeah yeah yeah so you threaten them if you don't get the food as soon as possible I will leave here

48 JL9: yeah yeah $\downarrow$

49 JT: hemmm good good $\downarrow$

JT nominates JL6 to answer his question in the initial RQ he asks. JL6 fills in the response slot in the already initiated Initiation-Response-Feedback (IRF) sequence in turn 2. The organization of the following turns indicates JT's intention to provide learners with more interactional space by eliciting more responses from them. This becomes evident with JT's constant follow-up question instead of the feedback move in the IRF sequence. An example is turn 3, where JT does not evaluate JL6's response and instead prompts her further with a follow-up question. This interactional practice seems to be aligned with JT's pedagogic goal until turn 6. In this turn and while JL6's turn has not come to a prosodic, phonological or semantic end, JT cuts her short. Notice the latching sign at the end of turn 6 and after JL6 says "but" which signals the initiation of JT's unwelcomed next turn. As the structure of the following turns characterized by multiple follow-up moves unravel, JT does so to help JT6 keep talking. His untimely follow-up question in turn 7 , however, opens up an insertion sequence demanding JL6 to respond to the newly asked question. This happens in turn 8 where JL6 says "over twenty minutes." Yet this is an answer to JT's "how long is too much for you like ten minutes? Twenty minutes?" and there is no more any room 
for her original sentence that could potentially follow her "but" in turn 6 . Quickly after this, another instance of untimely interruption occurs. JL's continuing sentence in turn 10 where she says "after" with a rising intonation is soon curtailed by JT who summarizes JL6's previous contribution. In the following turns, JL6 does not find any space for what she wanted to say in turn 10 either. JT's interruptions happen once again in turn 17 with very similar interactional results. In turn 16, and when JL6 is arguing how her part-time in a restaurant has taught her to be patient as a customer, JT's summary turn cuts her short. In turn 16 when she was saying "I can wait in the..." but the bracket before the end of her turn shows JT's utterance is concurrent with JL6's ongoing turn and this causes her to surrender her turn. Once again, she never finds the chance later to complete what she started in turn 16. All she can do before JT turns to another speaker is to utter a "yeah" in turn 18 as a confirmation for JT's previous turn.

At this point, JT nominates another next speaker who is JL14 with RQs asked and rephrased to elicit responses from her. Yet, in turn 25, another interruption happens which does not allow JL14 to have an extended contribution. While in turn 25 JL14 initiates a response, JT's next question does not even let her utter a word completely. JT's "but" in turn 26 shifts the focus once again, and JL14 does not get a chance to complete the word "smile" (smi-) in turn 25.

Another type of obstructive interactional practice happens in turn 45 when JT's interruption takes the form of a turn completion utterance. Starting in turn 32, JL9 has been nominated by JT as the next speaker requested implicitly to answer the same question the other two learners in this excerpt had answered. After a few exchanges, in turn 44, JL9 says what she does if the food she orders is served later than expected. She says that after waiting for a long time, she tells the waiter that she would leave the restaurant. Yet, it seems that JT could guess what JL9 wanted to say before she actually did so and consequently takes the turn to complete her ongoing utterance in turn 45. JT's prediction appears to be correct since JL9 does not repair what JT says. However, notice how this turn completion act brings JL9's comment to a premature end. The sequence then ends with JT's case closing "good good" with a falling intonation in turn 49.

\subsubsection{Undue elaboration on questions}

Another obstructive interactional practice identified is undue elaboration on questions, which can be defined as the sequence initiator's further elaborations on a question already asked. This practice is different from the obstructive role of prolonged teacher turns discussed above since while in the latter the whole turn is dedicated to asking a long $R Q$, in undue elaboration sequences the speaker talks about the question. In other words, while the question itself might be short and manageable, it is the extra elaboration on the question that causes a hindrance for a potential next speaker. Excerpt5.7 illustrates this point. In this excerpt, TT poses a question about the effects of vegetarian diets on the environment. This $R Q$, in the remainder of the sequence, however, does not generate extended responses since JT elaborates on his paraphrase of the original question more than is interactionally required. 


\section{Excerpt 6: Obstruction by undue elaboration}

1 TT: Do you think that ehm vegeTArian restaurant can be another kind of help for the environment? ((looking at the camera)) (5.0)

2 JT: can vegetarian restaurant be a kind of eco-friendly restaurant? ((to JLs)) (4.0)

3 TT: What do you think? ((to TLs)) (2.0) think about [it

4 TL12:

I] think it isn't I think it's not it's not necessary to be to see as a eco-friendly? Yeah eco-friendly restaurant because how you (.) how you dispose the trash or recycle it is (1.0) an big issue (2.0)

5 TT: but what if we consume less meat?

6 TL12: yes consume less meat is definitely ehm you less the carbon (.) footprint carbon footprint but I think it's not a (1.0) >it's not< a main factor of a definition of ((looks at TL15 sitting next to him))

7 TL15: eco-[friendly

8 TL12: $\quad$ yes] eco-friendly restaurant

9 JT: but carbon is really important isn't it? I mean the production of carbon is one of the major sources of pollution in the word now so if if going on a vegetarian diet can reDUCE the amount of carbon footprint in people I believe it's a major step (1.0)

10 TT: yeah

11 JT: well research has shown that non-vegetarian diets produce lots of carbon whereas vegetarian diets tend to produce much less carbon dioxide so if this is REALLY the case it is worth investing (1.0) >don't you think?< (7.0)

12 JT: ehm is there any a big e:::h well e:::hm a couple of years ago I remember organic food gained a lot of attention in many parts of the world (1.0) people >people< decided to spend a lot of money on organic food (.) do you remember anything? In Japan is that a like (.) kind of FAD like many people wanted to buy just organic food because they thought this is healthy? (2.0) e::hm has it been so in Taiwan? Specially younger generation AND the Female $>$ if $<$ if I'm not wrong (3.0)

The sequence starts with TT's RQ inquiring about the role vegetarian restaurants can play in saving the environment. There seems to be enough wait-time after this question, but since none of the TLs or JLs initiates a response for this question, in turn 2, JT paraphrases the question probably with the purpose of prompting JLs. After another long silence, TT prompts TLs once again and finally TL12 volunteers for a response. There is a follow-up question after TL12's initial response, which elicits even longer responses from him. The interaction goes on in line with TT's apparent purpose which is to make TLs talk more until in turn 9 the teacher tries to initiate another follow-up move for the already asked and paraphrased question in turn 1 . His lengthy elaboration about some other aspects of the question does not, however, lead to further responses, and the opportunity seems to have been lost. This is evident with the long pauses in turn 11 and the complete surrendering of the topic by JT in turn 12.

\section{Discussion and Implications}

The results of this CA-informed study showed that in addition to the type of questions asked, several other interactional practices can shape EFL learners' responses. More particularly, it identified four practices that have the potential to facilitate learner contributions and five practices that can obstruct them. These findings add to our current understanding of the role of teacher talk in eliciting response from learners in the language classroom. More specifically, with 
reference to research on question types in the EFL classroom, the results of the present study imply that while RQs are more likely to elicit lengthier responses from learners, the interactional contexts in which such questions are asked play far more important roles. This interpretation seems to show a contrast with what Shomossi (2004), David (2007) and Alduais (2012) found in their studies. While their research findings recommended EFL teachers to ask more RQs in the classroom, the results of the present study raises awareness toward the more complex nature of interaction in the classroom where failure to ask RQs in appropriate contexts, renders them less useful. The findings of this study are also resonant with what wider research on promoting space for learning and participation in the language classroom has offered so far. Similar to the present research, such studies have focused on the interactional structure of turns in classroom talk, for instance, by exploring how alternations in the initiation, response, and feedback (IRF) moves can impact learners' contributions and responses (Girgin \& Brnadt, 2019). It is also worth mentioning that, akin to the present study, most of these studies have employed CA as their methodological framework as the turn-by-turn analysis of classroom interaction is believed to have the potential to reveal how learners can achieve higher levels of agency in their own learning through increasing their participation and contribution in the classroom (McNamara, 2019).

The application of CA in studying question types also has implications for research on the co-construction of interaction in the classroom. The bottom line of such research is that it is the responsibility of all participants in a given conversation to make it work. Second and/or foreign language learners are often evaluated in terms of fluency. But is fluency an individual's attribute? Responding elaborately and smoothly to a question posed by a teacher does indeed indicate a learner's fluency. However, as the findings in this study suggest, it cannot be considered the learner per se that is making it happen. McCarthy (2005) used the term confluence instead of fluency to indicate that spoken language is made fluent by the endeavors of all speakers in a conversation and not only one of them. In the case of the present study, it can hence be argued that the way a teacher asks a question can influence how a learner responds to it. This can have multiple implications for how assessment, particularly the assessment of the speaking skill, is understood and undertaken in language pedagogy.

More importantly, the fact that teacher turns can exert important influences on the ensuing learner turns also implies that the development of teachers' CIC has to be taken more seriously in teacher training courses. In an era when prescriptive and knowledge-transmission models of teacher training can no longer be considered tenable, equipping teachers with microanalytic tools to study their own classroom interactive decisions can prove much more fruitful. Studying classroom interaction with a CA methodology may, of course, impose extra burdens on teachers. That is why the role of teacher trainers is even more prominent in this regard. The production of materials based on CA-informed research on classroom interaction can facilitate teachers' engagement with critical reflection on their classroom practices and consequently result in improvement in their classroom performance. 


\section{Conclusion}

The present paper set out to study how learner contributions can be shaped by teachers across question-answer sequences with a particular emphasis on interactional practices around RQs. Research on CIC (Walsh, 2013) has demonstrated how teachers' appropriate interactional decisions can create learning space and opportunities for learner participation in the classroom. In line with what such research has offered to date, in this study teachers' interactional practices before, during and after asking RQs were investigated with a conversation analytic methodology and categorized as either facilitative or obstructive for the elicitation of elaborate responses from learners, and consequently, for maximizing their participation opportunities. Facilitative practices identified in this study included asking RQs at TRPs, asking referential follow-up questions when a communicative breakdown emerges, teacher echoing of learner responses and paraphrasing the RQ already asked. On the other hand, practices including self-elaboration, self-answering, asking RQs in or after extended teacher turns, teacher interruptions and teacher turn completions were found to have obstructive effects on learners' responses. These results can inform both research and practice in language teaching, assessment, and materials development. Similarly, the results imply the need for considering the development of CIC in language teachers as a key component both in preservice and in-service teacher training programs. The present research built upon audio-recorded interactions among teachers and students in a COIL program. Yet, recent conversation analytic research has tended to incorporate video data in the analysis of classroom interaction as well. This enables researchers to attend to temporal and sequential organization of classroom interactions by teachers and learners (Mondada, 2016; Hall \& Looney, 2019). Further research utilizing video data may shed more light on the way teacher turns may facilitate or impede opportunities for extended learner participation in the language classroom.

\section{References}

Alduais, A. M. S. (2012). An account of teaching strategies which promote studentinitiation. Journal of Sociological Research, 3(2), 489-501. doi:10.5296/jsr.v3i2.2614

Brock, C. A. (1986). The effects of referential questions on ESL classroom discourse. TESOL Quarterly, 20(1), 47-59. doi:10.2307/3586388

Daşkın, B. C. (2015). Shaping learner contributions in an EFL classroom: Implications for L2 classroom interactional competence. Classroom Discourse, 6(1), 33-56. doi:10.1080/19463014.2014.911699

David, F. O. (2007). Teachers' questioning behavior and ESL classroom interaction pattern. Humanity \& Social Science Journal, 2(2), 127-131.

Farr, F., Farrell, A., \& Riordan, E. (2019). Social interaction in language teacher education. Edinburgh: Edinburgh University Press.

Girgin, U., \& Brandt, A. (2019). Creating space for learning through 'Mm hm' in an L2 classroom: Implications for L2 classroom interactional competence. Classroom Discourse, 1-19. doi:10.1080/19463014.2019.1603115

Hall, J. K., \& Looney, S. D. (2019). The embodied work of teaching. Bristol: Multilingual Matters.

Have, P. T. (2012). Doing conversation analysis. Los Angeles: Sage. 
Hosoda, Y., \& Aline, D. (2013). Two Preferences in Question-Answer Sequences in Language Classroom Context. Classroom Discourse, 4(1), 63-88. doi:10.1080/19463014.2013.783497

Jefferson, G. (1984). Transcription Notation. In J. Atkinson \& J. Heritage (Eds.), Structures of social interaction. New York: Cambridge University Press.

Kumaravadivelu, B. (1994). The Post-method condition: (E)merging strategies for second/foreign language teaching. TESOL Quarterly, 28(1), 27-48. doi: $10.2307 / 3587197$

Long, M., \& Sato. C. (1983). Classroom foreigner talk discourse: Forms and functions of teachers' questions. In H. Seliger, \& M. Long (Eds.), Classroom oriented research in second language acquisition (pp. 268-286). Rowley, MA: Newsbury House.

Markee, N. (2019). Some theoretical reflections on the construct of interactional competence. In M. R. Salaberry, \& S. Kunitz (Eds.), Teaching and testing L2 interactional competence: bridging theory and practice (pp. 60-76). New York, NY: Routledge.

McCarthy, M. J. (2005). Fluency and confluence: What fluent speakers do. The Language Teacher, 29(6), 26-28.

McNamara, T. (2019). Language and subjectivity. Cambridge: Cambridge University Press.

Mondada, L. (2016). Challenges of multimodality: Language and the body in social interaction. Journal of sociolinguistics, 20, 336-366. doi:10.1111/josl.1_12177

Richards, J. C. (1990). The Language Teaching Matrix. Cambridge: Cambridge University Press. doi:10.1017/cbo9780511667152.002

Salaberry, M. R., \& Kunitz, S. (2019). Teaching and testing L2 interactional competence: bridging theory and practice. New York, NY: Routledge.

Seedhouse, P. (2004). The interactional architecture of the language classroom: A conversation analysis perspective. Malden: Blackwell. doi:10.1093/applin/ami048

Schwab, G. (2011). From dialogue to multilogue: A different view on participation in the English foreign-language classroom. Classroom Discourse, 2(1), 3-19. doi:10.1080/19463014.2011.562654

Sert, O. (2011). A Micro-analytic investigation of claims of insufficient knowledge in EAL classrooms.Unpublished PhD dissertation, Newcastle University, Newcastle, England.

Sert, O. (2013). Epistemic status check as an interactional phenomenon in instructed learning settings. Journal of Pragmatics, 45, 13-28. doi:10.1016/j.pragma.2012.10.005

Shiozaki, H. (2016, January 21-22). Collaborative Online International Learning (COIL) for Critical Reading of Media: Collaboration between IIUM and Kansai University.Paper presented at the International Language and Tourism Conference, Kuala Lumpur, Malaysia.

Shomoossi, N. (2004). The effect of teachers' questioning behavior on EFL classroom introduction: A classroom research study. The Reading Matrix, 4(2), 24- 46.

Waer, H. H. E. (2012). Why that language, in that context, right now?: The use of theL1 in L2 classroom interaction in an Egyptian setting. Unpublished PhD dissertation, Newcastle University, Newcastle, England.

Walsh, S. (2002). Construction or obstruction: Teacher talk and learner involvement in the EFL Classroom. Language Teaching Research, 6(1), 3-23. doi:10.1191/13621688021r095oa

Walsh, S. (2006). Investigating classroom discourse. London: Routledge. doi:10.4324/9780203015711 
Walsh, S. (2011). Exploring Classroom Discourse. Oxon: Routledge. doi:10.4324/9780203827826

Walsh, S. (2013). Classroom discourse and teacher development. Edinburgh: Edinburgh University Press.

Walsh, S., \& Li, L. (2013). Conversations as space for learning. International Journal of Applied Linguistics, 23(2), 247-266. doi:10.1111/ijal.12005

Waring, H. Z. (2009). Moving out of IRF (Initiation-Response-Feedback): A single case analysis. Language Learning, 59(4), 796-824. doi:10.1111/j.1467-9922.2009.00526.x 
Appendix: Transcription Symbols, based on Jefferson (1984)

\begin{tabular}{|c|c|c|}
\hline Symbol & Name & Use \\
\hline [ text ] & Brackets & $\begin{array}{l}\text { Indicates the start and endpoints of } \\
\text { overlapping speech. }\end{array}$ \\
\hline$=$ & Equal Sign & $\begin{array}{l}\text { Indicates the break and subsequent } \\
\text { continuation of a single interrupted utterance. }\end{array}$ \\
\hline (\# of seconds) & Timed Pause & $\begin{array}{l}\text { A number in parentheses indicates the time, in } \\
\text { seconds, of a pause in speech. }\end{array}$ \\
\hline (.) & Micropause & A brief pause, usually less than 0.2 seconds. \\
\hline or $\downarrow$ & $\begin{array}{l}\text { Period or Down } \\
\text { Arrow }\end{array}$ & Indicates falling pitch. \\
\hline ? or $\uparrow$ & $\begin{array}{l}\text { Question Mark or Up } \\
\text { Arrow }\end{array}$ & Indicates a rising pitch. \\
\hline , & Comma & Indicates a temporary rise or fall in intonation. \\
\hline- & Hyphen & $\begin{array}{l}\text { Indicates an abrupt halt or interruption in } \\
\text { utterance. }\end{array}$ \\
\hline$>$ text $<$ & $\begin{array}{l}\text { Greater than / Less } \\
\text { than }\end{array}$ & $\begin{array}{l}\text { Indicates that the enclosed speech was } \\
\text { delivered more rapidly than usual for the } \\
\text { speaker. }\end{array}$ \\
\hline$<$ text $>$ & $\begin{array}{l}\text { Less than / Greater } \\
\text { than symbols }\end{array}$ & $\begin{array}{l}\text { Indicates that the enclosed speech was } \\
\text { delivered more slowly than usual for the } \\
\text { speaker. }\end{array}$ \\
\hline$\circ$ & Degree symbol & Indicates whisper or reduced volume speech. \\
\hline ALL CAPS & Capitalized text & Indicates shouted or increased volume speech. \\
\hline Underline & Underlined text & $\begin{array}{l}\text { Indicates the speaker is emphasizing or } \\
\text { stressing the speech. }\end{array}$ \\
\hline$: \because:$ & Colon(s) & Indicates prolongation of an utterance. \\
\hline (hhh) & & Audible exhalation \\
\hline ? or (.hhh) & High Dot & Audible inhalation \\
\hline ( text) & Parentheses & $\begin{array}{l}\text { Speech which is unclear or in doubt in the } \\
\text { transcript. }\end{array}$ \\
\hline$(($ italic text $))$ & Double Parentheses & Annotation of non-verbal activity. \\
\hline
\end{tabular}

